\title{
Prevalence and causes of visual impairment and blindness in three ecological regions of Nepal
}

\section{Mohan Krishna Shrestha ( $\nabla$ mksshrestha@gmail.com )}

Tilganga Institute of Ophthalmology https://orcid.org/0000-0003-4592-6715

\section{Sunjuri Zhi Yu Sun}

Monash University Tan Sri Jeffrey Cheah School of Medicine and Health Science

\section{Ben Limbu}

Tilganga Institute of Ophthalmology

\section{Manish Poudel}

Tilganga Institute of Ophthalmology

\section{Shankar Prasad Khanal}

Central department of Statistics, Tribhuvan University

\section{Bandana Pradhan}

Department of Community Medicine and Public Health, Institute of Medicine, Tribhuvan University

\section{Mangala Shrestha}

Central Department of Rural Development, Tribhuvan University

\section{Research article}

Keywords: Epidemiology, Public health, visual, Optic and refraction

Posted Date: November 22nd, 2019

DOl: https://doi.org/10.21203/rs.2.520/v5

License: (c) (i) This work is licensed under a Creative Commons Attribution 4.0 International License. Read Full License

Version of Record: A version of this preprint was published at Nepalese Journal of Ophthalmology on January 1st, 2021. See the published version at https://doi.org/10.3126/nepjoph.v13i1.29217. 


\section{Abstract}

Background: Visual impairment and blindness are significant public health issues worldwide. This study aimed to estimate the prevalence and causes of moderate to severe visual impairment (MSVI) and blindness in people aged 15 years and above across three ecological regions of Nepal. Methods: A comparative cross-sectional study was conducted in one district in each of the three ecological regions of Nepal. Intensive training was provided to health workers on how to conduct door-to-door enumeration, visual acuity testing and referral when indicated for comprehensive ocular examination by technicians and ophthalmologists to diagnose and treat ocular morbidities. Collected data were analyzed using Statistical Package for Social Science (SPSS) v19.0 and Stata v10.0 software. Results: Altogether 5234 participants were enrolled in the study (participation rate 96.4\%). The overall prevalence of MSVI was $9.5 \%(95 \% \mathrm{Cl}=8.7-10.3)$ which was $4.7 \%$ in the Mountain district, $11.2 \%$ in the Hill district and $21.2 \%$ in the Tarai district. In those aged 15-49 years MSVI prevalence was $1.5 \%$ and in those aged $\geq 50$ it was $25.1 \%$. The overall prevalence of blindness was $0.9 \%$ (95\% $\mathrm{Cl}=0.6-1.2)$, and the prevalence of blindness in the $15-49$ and $\geq 50$ age groups was $0.2 \%$ and $2.3 \%$ respectively. Most cases of visual impairment and blindness (95.5\%) were due to cataract and uncorrected refractive error. Overall, cataract was the leading cause of visual impairment and blindness (53.5\%), followed by uncorrected refractive error (39.5\%). Conclusion: The prevalence of visual impairment and blindness varied significantly with age, ethnicity and locality. The correction of refractive error and cataract surgery would reduce nine in ten cases of moderate to severe visual impairment and blindness. Key words: Epidemiology, Public health, visual, Optic and refraction

\section{Background}

Visual impairment including blindness is a major public health challenge, particularly in low- and middleincome settings [1]. More than $80 \%$ of individuals with visual impairment $(\mathrm{VI})$ and blindness live in developing countries where resources are scarce. The prevalence of visual impairment varies between and within countries, largely due to variations in accessibility, availability, affordability and acceptability of eye health services [2-4].

Previous studies have found that the prevalence of $\mathrm{VI}$ and blindness ranged from 10 to $35 \%$ across different age groups worldwide [5-7]. Prevalence of blindness is higher in females than males, which may be due to discrepancies in characteristics such as disease prevalence, utilisation of services and life expectancy[8, 9]. The Rapid Assessment of Avoidable Blindness (RAAB) survey conducted during 2008 to 2010 found that the prevalence of VI was $13.2 \%$ in the Bagmati and Janakpur zones of Nepal in those aged 50 years and above $[10,11]$.

Geographically, Nepal is a diverse country, with climate conditions ranging from tropical to frigid. Health problems, including ocular conditions, may differ across ecological regions due to dissimilar environmental characteristics, socioeconomic status and accessibility of eye health care. In order to achieve the targets of both the Vision 2020 goals, Global Action Plan (2014-2019) and the Sustainable 
Development Goals (SDGs) in Nepal, it is important to understand the burden of visual impairment in the rural community with independent and dependent population [12-14]. The correction of VI of younger people gives the potential to contribute to national economic growth, as many years of living with vision loss can be avoided. Therefore, reducing VI might be a good investment to improve the overall growth of Nepal. However, to date, there is a paucity of information available on the pattern of diseases across all ecological regions of Nepal. This study aims to investigate the prevalence and causes of moderate to severe visual impairment (MSVI) and blindness within these regions.

\section{Methods}

Study design

A comparative cross-sectional study was designed to determine the prevalence and causes of visual impairment and blindness in one district from each of Nepal's three ecological regions.

\section{Study Areas}

Nepal is divided into three ecological regions based on altitude and climatic conditions; namely the Mountain, Hill and Tarai (plain) regions. The Tilganga Institute of Ophthalmology, a tertiary eye centre, and its branches have been providing eye care services, mainly in the central development region of the Nepal. The study was conducted from January to December 2011. To explore the differences of ocular morbidity in different location, three districts, one from each ecological region were purposively selected for this study. The selected districts were Dolakha from the Mountain region, Dhading from the Hill region and Sarlahi from the Tarai region.

\section{Sample size}

There was no pre-existing information on the prevalence of visual impairment and blindness in people aged 15 to 49 by each ecological region in Nepal, so we conducted a pilot study to determine the prevalence of MSVI and blindness from at least 100 participants from one Village Development Committee randomly selected from each region. The result of the pilot study showed that the prevalence of MSVI and blindness was $7 \%$ in the mountain region, $11 \%$ in the hill region and $22 \%$ in the Tarai region.

Based on assumed prevalence of $14 \%$ in the population aged 15 years and above, with precision of $10 \%$ using $95 \%$ confidence interval and design effect of 2 , we determined the minimum required sample size was 4720 [15]. It was assumed that there would be $15 \%$ non-response rate. After considering this assumed non-response rate, initially the survey was attempted to 5428 participants. The number of participants from each region was distributed as per the findings of pilot study, with 2815 participants enrolled in Dolakha, 1509 in Dhading and 910 in Sarlahi. The participants from each region were enrolled when desired sample size was reached.

\section{Sampling procedure}


Village Development Committees (VDCs) with a population size $>4,000$ [11] were regarded as a cluster. Six clusters were randomly selected across the three districts. This resulted in one VDC selected in Sarlahi, two in Dhading and three in Dolakha.

\section{Inclusion criteria}

All residents were examined if they were aged 15 years and above, resided in the study areas and consented to the study during house-to-house surveys conducted by field assistants. Visual impairment and blindness was classified according to the ICD-10 classification system.[16] The causes of visual impairment were classified into the following categories: avoidable (treatable and preventable), posterior segment diseases and others. Individuals were considered non-participants if they did not consent to participation in the study, were unable to communicate or were absent during the survey even after 2-3 repeated visits.

Training and orientation:

Three days intensive skill based training was delivered to Community Medical Assistants on testing visual acuity; and detecting eye health abnormalities. The clinicians (ophthalmologist, ophthalmic technician) were oriented on the purpose of the research and the research protocol to maintain ethical standards in obtaining informed consent and delivering comprehensive eye examinations.

\section{Data collection}

General information including age, ethnicity etc, household, service utilization, financial and social information was collected through face-to-face interviews that were conducted during field administration in all districts. Visual acuity for distance (presenting visual acuity and best corrected visual acuity by pinhole) was tested by trained community medical assistants using E-Snellen chart at six meters distance. Participants with visual impairment (presenting visual acuity less than 6/18) and other ocular abnormalities were asked to return nearest place where feasible to participants and their visual acuity was verified by ophthalmic technicians. An ophthalmologist performed a comprehensive eye examination, including diffuse torch light examination, slit lamp biomicroscopy, direct and indirect ophthalmoscopy with dilated pupils. Participants identified with visual impairment during the house to house screening were invited to attend a nearby facility for visual acuity to be confirmed and a comprehensive eye examination undertaken

\section{Data Analysis}

Data were entered in Microsoft Excel 2007 and cleaned. SPSS V19 and Strata v10 were used for data analysis. Frequency, percentage and $95 \% \mathrm{Cl}$ were calculated. Chi square test / Fisher exact test was used for association for categorical data analysis. P-value $<0.05$ was considered as significant.

\section{Ethical consideration}


Ethical approval was granted by the Institutional Review Committee of the Tilganga Institute of Ophthalmology (IRC-TIO) and informed written consent was obtained from participants.

\section{Results}

Five thousand four hundred and twenty eight people were enumerated and 5234 enrolled $(96.4 \%)$ and had their visual acuity tested by enumerators during house-to-house visits. A total of 566 participants were found with visual impairment $(\mathrm{VI})$ including blindness. Of these participants with $\mathrm{Vl}, 24$ participants (4.2\%) were unable to complete this second examination by ophthalmic professionals. Of these $24,3.2 \%$

(5) were from Dolakha, 4.1\% (8) from Dhading and 5.2\% (11) from Sarlahi. Results from these individuals were not analysed further. Of the total diagnosed visual impairment participants including blindness, only 542 participants with MSVI and blindness (95.8\%) were included for analysis.

\section{Prevalence of visual impairment}

Presenting visual acuity of participants

About $90 \%$ (4692) of all examined participants (5324) had a presenting visual acuity of 6/6-6/18 (no or mild visual impairment, NMVI), whereas the proportion of participants with a visual acuity of $<6 / 18-3 / 60$ (moderate to severe visual impairment, MSVI) and $<3 / 60$ (blindness) was $9.5 \%$ (495), and $0.9 \%(47)$ respectively (Table 1). The highest prevalence of moderate to severe visual impairment was found in Sarlahi $(21.2 \%)$ followed by Dhading (11.2\%) and Dolakha (4.7\%). However, the highest prevalence of blindness was detected in Dhading district (1.2\%), followed by Sarlahi $(0.9 \%)$ and Dolakha $(0.7 \%)$. The difference in rates of MSVI and blindness between the three ecological regions was statistically significant $(p<0.0001)$.

Table 1: Prevalence of bilateral moderate to severe visual impairment and blindness

\begin{tabular}{|c|c|c|c|c|}
\hline $\begin{array}{l}\text { Vision } \\
\text { category }\end{array}$ & $\begin{array}{l}\text { All } \\
\text { n }(\%, 95 \% \mathrm{CI})\end{array}$ & $\begin{array}{l}\text { Dolakha } \\
\text { n }(\%, 95 \% \mathrm{CI})\end{array}$ & $\begin{array}{l}\text { Dhading } \\
\text { n (\%, 95\% CI) }\end{array}$ & $\begin{array}{l}\text { Sarlahi } \\
\text { n }(\%, 95 \% \mathrm{CI})\end{array}$ \\
\hline NMVI & $\begin{array}{lll}4692 & (89.6, \quad 88.8 \\
90.5) & & \end{array}$ & $\begin{array}{lll}2662 & (94.6,93.7 \\
95.3) & & \end{array}$ & $\begin{array}{lll}- & 1322 \\
89.3) & (87.6, & 85.9 \\
\end{array}$ & $\begin{array}{llll}-708 & (77.8, & 74.8 \\
& 80.5)\end{array}$ \\
\hline MSVI & $495(9.5,8.7-10.3)$ & $133(4.7,4.0-5.5)$ & $169(11.2,9.6-12.9)$ & $\begin{array}{lll}193 & (21.2, & 18.7 \\
-24.0) & \end{array}$ \\
\hline Blindness & $47(0.9,0.6-1.2)$ & $20(0.7,0.4-1.1)$ & $18(1.2,0.7-1.7)$ & $9(1.0,0.4-1.8)$ \\
\hline Total & $5234(100.0)$ & $2815(100.0)$ & $1509(100.0)$ & $910(100.0)$ \\
\hline
\end{tabular}

Note: $\chi^{2}=229.57, \mathrm{p}<0.001 . N M V I=6 / 6-6 / 18, M S V I=<6 / 18-3 / 60$, Blind $=<3 / 60$ 
Approximately $98 \%$ of the participants aged 15 to 49 years had no or mild $\mathrm{VI}$, compared to $72.6 \%$ in the age group of 50 and above. The prevalence of moderate to severe visual impairment was $25.1 \%$ in participants aged 50 years and above, and of these, $22.9 \%$ of participants were diagnosed with Moderate VI. More than $2 \%$ of participants were diagnosed with blindness, as opposed to $0.2 \%$ in the 15 to 49 age group. Over $90 \%$ of participants belonging to the Hill caste and Janajatis ethnicity groups had normal visual or mild visual impairment. Moderate VI was more prevalent in the Tarai/Madhesi caste (18\%), followed by the Muslim group (16\%). Rates of blindness was highest within the Muslim group (2.3\%), followed by the Madhesi caste (1.3\%) and the Dalit ethnicity group (1.2\%) (Table 2).

Table 2: Types of bilateral visual impairment and blindness by age and ethnicity

\begin{tabular}{|c|c|c|c|c|c|c|c|}
\hline \multicolumn{2}{|l|}{ Variables } & Total & $\begin{array}{l}\text { NMVI } \\
\text { n (\%) }\end{array}$ & $\begin{array}{l}\text { MSVI } \\
\mathrm{n}(\%)\end{array}$ & $\begin{array}{l}\text { Blind } \\
\mathrm{n}(\%)\end{array}$ & $\chi^{2}$ & $\mathrm{p}$-value \\
\hline \multirow[t]{3}{*}{ Age } & $15-49$ & 3470 & 3412 (98.3) & $52(1.5)$ & $6(0.2)$ & \multirow{3}{*}{836.48} & \multirow[t]{3}{*}{0.000} \\
\hline & $\geq 50$ & 1764 & 1280 (72.6) & $443(25.1)$ & $41(2.3)$ & & \\
\hline & Total & 5234 & 4692 (89.6) & 495 (9.5) & $47(0.9)$ & & \\
\hline \multirow[t]{6}{*}{ Ethnicity } & Hill caste & 2408 & 2235 (92.8) & $156(6.4)$ & $17(0.7)$ & \multirow[t]{6}{*}{157.04} & \multirow[t]{6}{*}{0.000} \\
\hline & Tarai/ Madhesi & 537 & $408(76)$ & $122(22.7)$ & $7(1.3)$ & & \\
\hline & Dalit & 515 & 462 (89.7) & $47(9.1)$ & $6(1.2)$ & & \\
\hline & Janajatis & 1643 & $1484(90.3)$ & $145(8.8)$ & $14(0.9)$ & & \\
\hline & Muslim & 131 & 103 (78.6) & $25(19.1)$ & $3(2.3)$ & & \\
\hline & Total & 5234 & $4692(89.6)$ & $495(9.5)$ & $47(0.9)$ & & \\
\hline
\end{tabular}

Note: $N M V I=6 / 6-6 / 18, M S V I=<6 / 18-3 / 60$, Blind $=<3 / 60$

\section{Causes of visual impairment}

Principal causes of bilateral visual impairment including blindness by location

The majority of visual impairment including blindness (93.7\%) were due to a treatable cause, such as uncorrected refractive error (URE), untreated cataract and uncorrected aphakia (Table 4). Approximately $2 \%$ of causes were preventable, namely those due to surgical complications, trachoma, phthisis and other corneal scars.

Treatable causes were highest in Dhading (95.7\%), followed by Sarlahi (94.6\%) and Dolakha (90.6\%), while preventable causes of visual impairment were highest in Sarlahi $(2.5 \%)$, followed by Dolakha (2.1\%) and Dhading $(0.5 \%)$. The potentially preventable causes of visual impairment including blindness were highest in Sarlahi $(2.5 \%)$ and lowest in Dhading (0.5\%). Thus, the proportion of visual impairment due to avoidable causes was $97 \%, 96 \%$ and $92 \%$ in Sarlahi, Dhading and Dolakha respectively.

Table 3 Principal causes of bilateral visual impairment including blindness by location 


\begin{tabular}{|c|c|c|c|c|c|c|}
\hline \multirow[t]{2}{*}{ Diseases } & \multicolumn{3}{|l|}{ Location } & \multicolumn{2}{|c|}{ Age (Years) } & \multirow{2}{*}{$\begin{array}{l}\text { All } \\
\text { n (\%) }\end{array}$} \\
\hline & $\begin{array}{l}\text { Dolakha } \\
\text { n (\%) }\end{array}$ & $\begin{array}{l}\text { Dhading } \\
\text { n (\%) }\end{array}$ & $\begin{array}{l}\text { Sarlahi } \\
\text { n (\%) }\end{array}$ & $\begin{array}{l}15-49 \\
\text { n (\%) }\end{array}$ & $\begin{array}{ll}50 & \text { and } \\
\text { older } & \\
\text { n (\%) } & \end{array}$ & \\
\hline $\begin{array}{l}\text { Uncorrected Refractive } \\
\text { Error }\end{array}$ & $\begin{array}{l}62 \\
(40.5)\end{array}$ & $\begin{array}{l}109 \\
(58.3)\end{array}$ & $\begin{array}{l}43 \\
(21.3)\end{array}$ & $\begin{array}{l}35 \\
(60.3)\end{array}$ & $179(37.0)$ & $\begin{array}{l}214 \\
(39.5)\end{array}$ \\
\hline Cataract, untreated & $\begin{array}{l}76 \\
(49.7)\end{array}$ & $\begin{array}{l}70 \\
(37.4)\end{array}$ & $\begin{array}{l}144 \\
(71.3)\end{array}$ & $\begin{array}{l}12 \\
(20.7)\end{array}$ & $278(57.4)$ & $\begin{array}{l}290 \\
(53.5)\end{array}$ \\
\hline Aphakia, uncorrected & $0(0.0)$ & $0(0.0)$ & $4(2.0)$ & $0(0.0)$ & $4(0.8)$ & $4(0.7)$ \\
\hline Surgical complications & $1(0.7)$ & $0(0.0)$ & $1(0.5)$ & $0(0.0)$ & $2(0.4)$ & $2(0.4)$ \\
\hline Trachoma & $0(0.0)$ & $0(0.0)$ & $3(1.5)$ & $1(1.7)$ & $2(0.4)$ & $3(0.6)$ \\
\hline Phthisis & $1(0.7)$ & $0(0.0)$ & $0(0.0)$ & $0(0)$ & $1(0.2)$ & $1(0.2)$ \\
\hline Other corneal scar & $1(0.7)$ & $1(0.5)$ & $1(0.5)$ & $0(0)$ & $3(0.6)$ & $3(0.6)$ \\
\hline Glaucoma & $3(2.0)$ & $1(0.5)$ & $4(2.0)$ & $5(8.6)$ & $3(0.6)$ & $8(1.5)$ \\
\hline Diabetic retinopathy & $0(0.0)$ & $0(0.0)$ & $1(0.5)$ & $0(0)$ & $1(0.2)$ & $1(0.2)$ \\
\hline ARMD & $2(1.3)$ & $1(0.5)$ & $0(0.0)$ & $0(0)$ & $3(0.6)$ & $3(0.6)$ \\
\hline $\begin{array}{l}\text { Other } \\
\text { segment/CNS }\end{array}$ & $6(3.9)$ & $2(1.1)$ & $1(0.5)$ & $3(5.2)$ & $6(1.2)$ & $9(1.7)$ \\
\hline Others & $1(0.7)$ & $3(1.6)$ & $0(0.0)$ & $0(0.0)$ & $0(0.0)$ & $4(0.7)$ \\
\hline Total & $\begin{array}{l}153 \\
(100)\end{array}$ & $\begin{array}{l}187 \\
(100)\end{array}$ & $\begin{array}{l}202 \\
(100)\end{array}$ & $\begin{array}{l}58 \\
(100)\end{array}$ & $484(100)$ & $\begin{array}{l}542 \\
(100)\end{array}$ \\
\hline
\end{tabular}

Principal causes of bilateral visual impairment including blindness by age

The principal causes of bilateral visual impairment including blindness were different between the two age groups (Table 4). In the 15 to 49 age group, uncorrected refractive error was the leading cause of visual impairment $(60.3 \%)$, followed by untreated cataract $(20.7 \%)$. Both of these causes are correctable, thus the percentage of correctable $\mathrm{VI}$ in this age group is $81 \%$. For the 50 years and over age group, untreated cataract was the leading cause of visual impairment $(58.7 \%)$, followed by uncorrected refractive error (37\%). Treatable causes of VI were higher in the 50 years and older age group (95.2\%) compared to the under 50 age group $(81.0 \%)$, however the prevalence of preventable VI was the same in both groups $(1.7 \%)$. In total, $95.4 \%$ of all VI cases were avoidable.

Bilateral correctable visual impairment including blindness by age and location

The Visual impairment was low in participants below 50 years of age (1.7\%), compared to participants aged 50 years and above (27.4\%). However, the percentage of correctable visual impairment in the 15-49 years and $\geq 50$ age groups were similar ( $55.2 \%$ and $56.2 \%$ respectively). The percentage of treatable visual impairment was highest in Dhading at $83 \%$, followed by $60 \%$ in Dolakha and $28 \%$ in Sarlahi (Table 3). 
Table 4: Bilateral correctable visual impairment and blindness by age and location

\begin{tabular}{|c|c|c|c|c|c|c|c|c|}
\hline \multirow{3}{*}{$\begin{array}{l}\text { Age } \\
\text { group } \\
\text { (years) }\end{array}$} & \multicolumn{6}{|l|}{ Location } & \multicolumn{2}{|l|}{ All } \\
\hline & Dolakha & & Dhading & & Sarlahi & & & \\
\hline & $\begin{array}{l}\text { Total } \\
\text { PVIB, n }\end{array}$ & $\begin{array}{l}\text { CVIB, n } \\
\text { (\%) }\end{array}$ & $\begin{array}{l}\text { Total } \\
\text { PVIB, } \mathrm{n}\end{array}$ & $\begin{array}{l}\text { CVIB, n } \\
(\%)\end{array}$ & $\begin{array}{l}\text { Total } \\
\text { PVIB, n }\end{array}$ & $\begin{array}{l}\text { CVIB, n } \\
\text { (\%) }\end{array}$ & $\begin{array}{l}\text { Total } \\
\text { PVIB, n }\end{array}$ & $\begin{array}{l}\text { CVIB, n } \\
(\%)\end{array}$ \\
\hline $15-49$ & 7 & 1 (14.3) & 28 & $\begin{array}{l}22 \\
(78.6)\end{array}$ & 23 & $9(39.1)$ & 58 & $\begin{array}{l}32 \\
(55.2)\end{array}$ \\
\hline$\geq 50$ & 146 & $\begin{array}{l}91 \\
(62.3)\end{array}$ & 159 & $\begin{array}{l}133 \\
(83.6)\end{array}$ & 179 & $\begin{array}{l}48 \\
(26.8)\end{array}$ & 484 & $\begin{array}{l}272 \\
(56.2)\end{array}$ \\
\hline Total & 153 & $\begin{array}{l}92 \\
(60.1)\end{array}$ & 187 & $\begin{array}{l}155 \\
(82.9)\end{array}$ & 202 & $\begin{array}{l}57 \\
(28.2) \\
\end{array}$ & 542 & $\begin{array}{l}304 \\
(56.1)\end{array}$ \\
\hline
\end{tabular}

Note $=$ PVIB- Presenting Visual Impairment and blindness, CVIB- Correctable Visual Impairment and blindness

\section{Discussion}

We found that the prevalence of visual impairment was $1.7 \%$ in the $15-49$ age group and $27.4 \%$ in those aged 50 years and above. We found the prevalence estimate in the study among those 50 years and above $(25.1 \%)$ was higher than the national estimate of $17.1 \%$ from the RAAB survey between 2008 and 2010 [11]. Few studies have been conducted in the young population aged 15 to 49 years, but our findings of prevalence of visual impairment are similar to estimates from a Northern Indian population [17].

Geographically, Nepal is divided into three ecological regions, each having its own unique culture and climate. To date, there have been a paucity of eye health studies conducted over these different regions. This study explored the prevalence of MSVI and blindness in all regions and found that it there were vast differences across the locations. The prevalence of visual impairment and blindness was found to be one in twenty participants in Dolakha (Mountain) district, one in eight in Dhading (Hill) district and one in five in Sarlahi (Tarai) district. It indicated that the overall prevalence of visual impairment was lowest in Dolakha and highest in Sarlahi which is comparable as mountain and plain areas with previous study conducted in others parts of the Nepal [18], Northern India [17, 19] and Tibetan autonomous areas of China [20].

Based on presenting visual acuity, 542 cases of MSVI and blindness were found during the survey (153 from Dolakha, 187 from Dhading and 202 from Sarlahi). After correction via pinhole, it was found that $56 \%$ of uncorrected refractive error was not visual impaired. This demonstrates that more than half of the visual impaired participants found in this study can be treated by correction of refractive error. This can be achieved by using simple procedures at the community level with low investment and does not necessitate patients needing to attend and receive treatment at well-equipped clinics or hospitals. Those findings is similar with previous study conducted at Karnali zone of Nepal. 
Cataract was the leading cause of MSVI and blindness followed by uncorrected refractive error. In total, about ninety five percent of all VI cases were due to avoidable causes by cataract operation and correction of refractive error. Uncorrected refractive error was the leading cause of visual impairment in the 15 to 49 age group, whereas cataracts were the leading cause in the 50 years and over age group [11, 21].

This study has a number of limitations. Small VDCs were excluded from the sample frame which limits generalizability of the findings. In addition, although differences were found in the different geographical areas, the findings may not be generalized beyond the study districts within each region. There were also strengths. For example, the team returned more than once to provide a range of opportunities for participants to attend the comprehensive examination, which meant participation rates were high.

\section{Conclusion}

In conclusion, the prevalence of MSVI and blindness was found one in ten participants across the three regions. In terms of ocular conditions, cataracts and its sequelae and refractive error were the main causes of moderate to severe visual impairment and blindness, though the prevalence of these conditions differed from region to region. The correction of refractive error and cataract surgery would eliminate nine in ten cases of visual impairment including blindness. The findings of the study can be used to set priorities of the eye care services across the three ecological regions in Nepal.

\section{Abbreviations}

ICD: International Classification of Diseases; NMVI: None or Mild Visual Impairment, MSVI: Moderate to Severe Visual Impairment; RAAB: Rapid Assessment of Avoidable Blindness; SDG: Sustainable Development Goals; VDC: Village Development Committees; VI: Visual Impairment.

\section{Declarations}

- Ethics approval and consent to participate: Ethical approval was granted by the Institutional Review Committee of the Tilganga Institute of Ophthalmology (IRC-TIO). Informed written consent was obtained from adult participants and consent of child (age below 18 years) was obtained from parent or guardian.

- Consent for publication: Not Applicable

- Availability of data and material: The datasets analysed during the current study are not publicly available due data confidentiality but are available from the corresponding author on reasonable request.

- Competing interests: No conflict of interest 
- Funding: Supported for logistics and field activities of research by The Fred Hollows Foundation, Australia

- Authors' contributions: MKS planned and conducted the study, analysed the data, and drafted and revised the paper. SS analysed the data, and drafted and revised the paper. BL conducted the study and revised the paper. MP cleaned and analysed the data, and revised the paper. SK, BP and MS planned the study and revised the paper.

- Acknowledgements: We sincerely thanks to Prof. Dr Sanduk Ruit, Dr. Reeta Gurung, Prof. Dr. Govinda Paudyal , Prof. Dr. Suman S Thapa from Tilganga Institute of Ophthalmology and Dr. Anil Subedi from Fred Hollows Foundation for their continuous support and encouragement.

- Author details: ${ }^{1}$ Research Department, Tilganga Institute of Ophthalmology, Kathmandu, Nepal, ${ }^{2}$ Monash University, Melbourne, Australia, ${ }^{3}$ Orbit, Plastic and Lacrimal clinic, Tilganga Institute of Ophthalmology, Kathmandu, Nepal, ${ }^{4}$ Central Department of Statistics, Tribhuvan University, Kathmandu, Nepal, ${ }^{5}$ Department of Community Medicine and Public Health, Institute of Medicine, Tribhuvan University, Kathmandu, Nepal, ${ }^{6}$ Central Department of Rural Development, Tribhuvan University, Kathmandu, Nepal

\section{References}

1. Stevens GA, White RA, Flaxman SR, Price H, Jonas JB, Keeffe J, Leasher J, Naidoo K, Pesudovs K, Resnikoff $S$ et al: Global Prevalence of Vision Impairment and Blindness. Ophthalmology, 120(12):2377-2384.

2. Bourne RRA, Flaxman SR, Braithwaite T, Cicinelli MV, Das A, Jonas JB, Keeffe J, Kempen JH, Leasher $\mathrm{J}$, Limburg $\mathrm{H}$ et al: Magnitude, temporal trends, and projections of the global prevalence of blindness and distance and near vision impairment: a systematic review and meta-analysis. Lancet Glob Health, 5(9):e888-e897.

3. Obrist B, Iteba N, Lengeler C, Makemba A, Mshana C, Nathan R, Alba S, Dillip A, Hetzel MW, Mayumana I et al: Access to health care in contexts of livelihood insecurity: a framework for analysis and action. PLoS Med 2007, 4(10):1584-1588.

4. WHO: Action plan for the prevention of avoidable blindness and visual impairment 2014-2019. Universal eye health: a global action plan 2014-2019. In. Geneva: World Health Organization; 2013.

5. Pascolini D, Mariotti SP: Global estimates of visual impairment: 2010. Br J Ophthalmol 2012, 96(5):614.

6. Global, regional, and national incidence, prevalence, and years lived with disability for 310 diseases and injuries, 1990-2015: a systematic analysis for the Global Burden of Disease Study 2015. Lancet 2016, 388(10053):1545-1602.

7. Resnikoff S, Pascolini D, Etya'ale D, Kocur I, Pararajasegaram R, Pokharel GP, Mariotti SP: Global data on visual impairment in the year 2002. Bull World Health Organ 2004, 82(11):844-851. 
8. Courtright P: Gender and blindness: Taking a global and a local perspective. Oman J Ophthalmol 2009, 2(2): 55-56.

9. Apex Body for Eye Health: Mid term review of vision 2020: The Right to Sight, Nepal In. Edited by Population MOHa. Kathmandu, Nepal: Ministry of Health; 2011.

10. Pradhan S, Deshmukh A, Giri Shrestha P, Basnet P, Kandel RP, Lewallen S, Sapkota YD, Bassett K, Yin VT: Prevalence of blindness and cataract surgical coverage in Narayani Zone, Nepal: a rapid assessment of avoidable blindness (RAAB) study. Br J Ophthalmol 2018, 102(3):291.

11. Nepal Netra Jyoti Sangh: The Epidemiology of Blindness in Nepal 2012. In. Kathmandu Nepal Netra Jyoti Sangh, Nepal; 2012.

12. WHO: Universal eye health: a global action plan 2014-2019. In. Geneva: World Health Organization; 2013.

13. Frick KD, Foster $A$ : The magnitude and cost of global blindness: an increasing problem that can be alleviated. Am J Ophthalmol 2003, 135(4):471-476.

14. Pizzarello L, Abiose A, Ffytche T, et al.: Vision 2020: The right to sight: a global initiative to eliminate avoidable blindness. Arch Ophthalmol 2004, 122(4):615-620.

15. Naing L, Winn T, Rusll B: Practical issues in calculating the sample size for prevalence studies. Archives of orofacial sciences 2006, 1:9-14.

16. WHO: International Statistical Classification of Diseases and Related Health Problems. In., vol. I-III, 10 edn. Geneva: World Health Organization; 2006.

17. Malhotra S, Vashist P, Gupta N, Kalaivani M, Rath R, Gupta SK: Prevalence and causes of visual impairment among adults aged 15-49 years in a rural area of north India - A population-based study. Indian J Ophthalmol 2018, 66(7):951-956.

18. Gurung KB, Pandey S, Shrestha MK, Gurung R, Ruit S: Prevalence Study of Visual Impairment and Blindness in Population of Mountainous Areas of Nepal. J Community Med Health Care 2017, 2(3):1015.

19. Malhotra S, Vashist P, Kalaivani M, Gupta N, Senjam SS, Rath R, Gupta SK: Prevalence and causes of visual impairment amongst older adults in a rural area of North India: a cross-sectional study. $B M J$ open 2018, 8(3):e018894.

20. Zhao J, Ellwein LB, Cui H, Ge J, Guan H, Lv J, Ma X, Yin J, Yin ZQ, Yuan Y et al: Prevalence of vision impairment in older adults in rural China: the China Nine-Province Survey. Ophthalmology 2010, 117(3):409-416, 416 e401.

21. Dulal S, Sapkota YD: Prevalence of blindness and visual impairment and its causes among people aged 50 years and above in Karnali Zone, Nepal. Nepal J Ophthalmol 2012, 4(2):282-287. 